\title{
Use of Mobile Devices to Measure Outcomes in Clinical Research, 2010-2016: A Systematic Literature Review
}

\author{
Brian Perry ${ }^{a, b}$ Will Herrington ${ }^{c}$ Jennifer C. Goldsack ${ }^{b, d}$ \\ Cheryl A. Grandinetti ${ }^{\text {e Kaveeta P. Vasisht }}{ }^{\mathrm{C}}$ Martin J. Landray ${ }^{\mathrm{c}}$ \\ Lauren Bataille $^{f}$ Robert A. DiCiccog Corey Bradley ${ }^{h}$ Ashish Narayan ${ }^{\mathrm{i}}$ \\ Elektra J. Papadopoulos ${ }^{\mathrm{e}}$ Nirav Sheth $^{\mathrm{j}}$ Ken Skodacek $^{\mathrm{k}}$ Komathi Stem $^{\mathrm{I}}$ \\ Theresa V. Strong ${ }^{\mathrm{m}}$ Marc K. Walton ${ }^{\mathrm{n}}$ Amy Cornelia, ${ }^{\mathrm{b}}$ \\ aDepartment of Population Health Sciences, Duke University School of Medicine, \\ Durham, NC, USA; ${ }^{b}$ Clinical Trials Transformation Initiative, Durham, NC, USA; \\ 'Nuffield Department of Population Health, University of Oxford, Oxford, UK; \\ ${ }^{\mathrm{d}}$ Duke Clinical Research Institute, Durham, NC, USA; ${ }^{e}$ Center for Drug Evaluation \\ and Research, US Food and Drug Administration, Silver Spring, MD, USA; \\ ${ }^{f}$ The Michael J. Fox Foundation for Parkinson's Research, New York, NY, USA; \\ g GlaxoSmithKline, King of Prussia, PA, USA; h Duke University Hospital, Durham, NC, USA; \\ 'Mount Sinai Health System, New York, NY, USA; ${ }^{j}$ MicroMedicine, Watertown, MA, USA; \\ ${ }^{k}$ Center for Devices and Radiological Health, US Food and Drug Administration, \\ Silver Spring, MD, USA; ' monARC Bionetworks, Palo Alto, CA, USA; ${ }^{m}$ Foundation for \\ Prader-Willi Research, Walnut, CA, USA; ${ }^{n}$ Janssen Research and Development, \\ Titusville, NJ, USA
}

\section{Keywords}

Clinical trials · Outcome assessments · Mobile devices · Endpoints · Physical activity · Sleep - Mobility · Biomarkers · Cardiac biomarkers - Respiratory biomarkers · Glucose · Gastric reflux $\cdot$ Inertial injury

\section{Abstract}

Background: The use of mobile devices in clinical research has advanced substantially in recent years due to the rapid pace of technology development. With an overall aim of informing the future use of mobile devices in interventional clinical research to measure primary outcomes, we conducted a systematic review of the use of and clinical outcomes measured by mobile devices (mobile outcomes) in observational and interventional clinical research. Method: We conducted a PubMed search using a range of search terms to retrieve peer-reviewed articles on clinical research published between January 2010 and May 2016 in which mobile devices were used to measure study outcomes. We screened each publication for specific inclusion and exclusion criteria. We then identified and qualitatively summarized the use of mobile outcome assessments in clinical research, including the type and design of the study, 
Perry et al.: Use of Mobile Devices to Measure Outcomes in Clinical Research, 2010-2016: A Systematic Literature Review

therapeutic focus, type of mobile device(s) used, and specific mobile outcomes reported. $\boldsymbol{R e}$ sults: The search retrieved 2,530 potential articles of interest. After screening, 88 publications remained. Twenty-five percent of the publications $(n=22)$ described mobile outcomes used in interventional research, and the rest $(n=66)$ described observational clinical research. Thirteen therapeutic areas were represented. Five categories of mobile devices were identified: (1) inertial sensors, (2) biosensors, (3) pressure sensors and walkways, (4) medication adherence monitors, and (5) location monitors; inertial sensors/accelerometers were most common (reported in $86 \%$ of the publications). Among the variety of mobile outcomes, various assessments of physical activity were most common (reported in $74 \%$ of the publications). Other mobile outcomes included assessments of sleep, mobility, and pill adherence, as well as biomarkers assessed using a mobile device, including cardiac measures, glucose, gastric reflux, respiratory measures, and intensity of head-related injury. Conclusion: Mobile devices are being widely used in clinical research to assess outcomes, although their use in interventional research to assess therapeutic effectiveness is limited. For mobile devices to be used more frequently in pivotal interventional research - such as trials informing regulatory decisionmaking - more focus should be placed on: (1) consolidating the evidence supporting the clinical meaningfulness of specific mobile outcomes, and (2) standardizing the use of mobile devices in clinical research to measure specific mobile outcomes (e.g., data capture frequencies, placement of device). To that aim, this manuscript offers a broad overview of the various mobile outcome assessments currently used in observational and interventional research, and categorizes and consolidates this information for researchers interested in using mobile devices to assess outcomes in interventional research.

(C) 2018 The Author(s)

Published by S. Karger AG, Basel

\section{Introduction}

Assessments of clinical outcomes that are meaningful to patients and that can accurately and reliably measure the potential therapeutic effects of an intervention are needed [1]. Advances in mobile devices, such as wearables and other remote sensors, may provide opportunities to develop new, valuable clinical outcome assessments which may help to accelerate the development of new treatments for patients. Mobile devices offer the potential to collect objective data from research participants with greater frequency than conventional data collection methods (e.g., paper diaries/surveys or clinician/staff observations not using mobile technology), as well as the opportunity to collect data outside of structured research settings, during activities of daily living. Outcome assessments that are made using a mobile device (mobile outcomes) include new ways of measuring traditional clinical outcomes and biomarkers [2, 3], as well as completely novel outcomes that would not be possible without the use of a mobile device. The use of mobile devices in clinical research may provide opportunities to assess disease burden and therapeutic effectiveness in ways that are sensitive, reliable, and relevant to patients' daily lives. Mobile devices may also decrease the burden of trial participation among both patients and research staff, and expand access to patients who typically do not have opportunities to participate in research.

The Clinical Trials Transformation Initiative (CTTI) is a public-private partnership co-founded by the US Food and Drug Administration and Duke University whose mission is to develop and drive the adoption of practices that will increase the quality and efficiency of clinical trials. CTTI observed that while the use of mobile devices in clinical research has increased in recent years, given technological advances, the integration of mobile devices into interventional research - specifically, randomized controlled trials (RCTs) - appears to have evolved at a much slower rate. Given the potential of mobile devices to improve clinical 
Perry et al.: Use of Mobile Devices to Measure Outcomes in Clinical Research, 2010-2016: A Systematic Literature Review

outcome assessments, CTTI aims to inform the development of new mobile outcome assessments for use in future clinical research - particularly in pivotal RCTs and trials to inform regulatory decision-making - by systematically describing recent uses of mobile devices in clinical research. Through such a review, we hope to describe the current state of the field and indicate where efforts to develop and include mobile outcome assessments for use in clinical trials have been concentrated to date. To the best of our knowledge, there has been no other effort to systematically consolidate the available peer-reviewed literature reporting the use of mobile outcome assessments in clinical research across various therapeutic areas.

\section{Methods}

We conducted a systematic search of peer-reviewed literature indexed in PubMed and published between January 2010 and May 2016. For the purpose of this review, we chose not to limit the scope of our search to any single therapeutic area or study design, assuming that all study designs (observational or interventional) could inform our aim. The search terms and inclusion and exclusion criteria used for identifying publications were developed in collaboration with a medical librarian and a multidisciplinary research team, including representatives from the US Food and Drug Administration, academia, the pharmaceutical industry, patient advocacy organizations, and mobile device experts [4]. Appendix 1 provides a complete list of the search terms.

Publications were selected for inclusion if they met all the following criteria: (1) the study focused on a stated therapeutic area or health condition; (2) the study used a mobile device to measure and record study outcomes outside of a research clinic setting (i.e., remote data capture); (3) the mobile device collected objective data; and (4) the study assessed the effect of an assigned intervention (i.e., interventional trials) or monitored exposures and health conditions of participants (i.e., observational studies). Studies that solely examined feasibility or measured only subjective data (e.g., patient-reported outcomes [PROs]) were excluded, as were meta-analyses.

Three steps were taken to assess the relevance of each publication identified in the search. First, two trained analysts independently reviewed the titles of all publications and identified those that they believed did not meet the inclusion criteria. Publications were excluded if both analysts independently determined that the publication was not relevant. Second, two analysts independently applied the inclusion/exclusion criteria to the remaining publications by reviewing the abstracts; differences in the reviewers' assessment of eligibility were resolved by a third analyst. Third, for the publications that remained, two analysts reviewed the full text of the publication for final confirmation of eligibility.

To organize and extract the relevant information from the final publications, we used NVivo, a qualitative data analysis software program [5]. We identified and extracted the following information from each publication: (1) the design (i.e., interventional trial vs. observational study) [6] and type of clinical research (e.g., treatment, prevention, epidemiological) [7]; (2) therapeutic conditions under investigation; (3) mobile device(s) used; (4) mobile outcome assessments and conventionally measured outcome assessments reported; (5) placement of the device; (6) sampling rate; (7) whether the mobile outcome assessment was used to measure a primary, co-primary (where the outcome was one of several deemed necessary to measure an intervention effect or change over time in the study), secondary, or exploratory endpoint; and (8) overall study objectives. Next, we applied current descriptions of outcome assessments (i.e., biomarkers, performance outcomes, observer-reported outcomes, clinician-reported outcomes, and PROs] [2, 3] to all assessments reported in the publications. We then grouped the mobile outcomes according to how they were used in the 
Perry et al.: Use of Mobile Devices to Measure Outcomes in Clinical Research

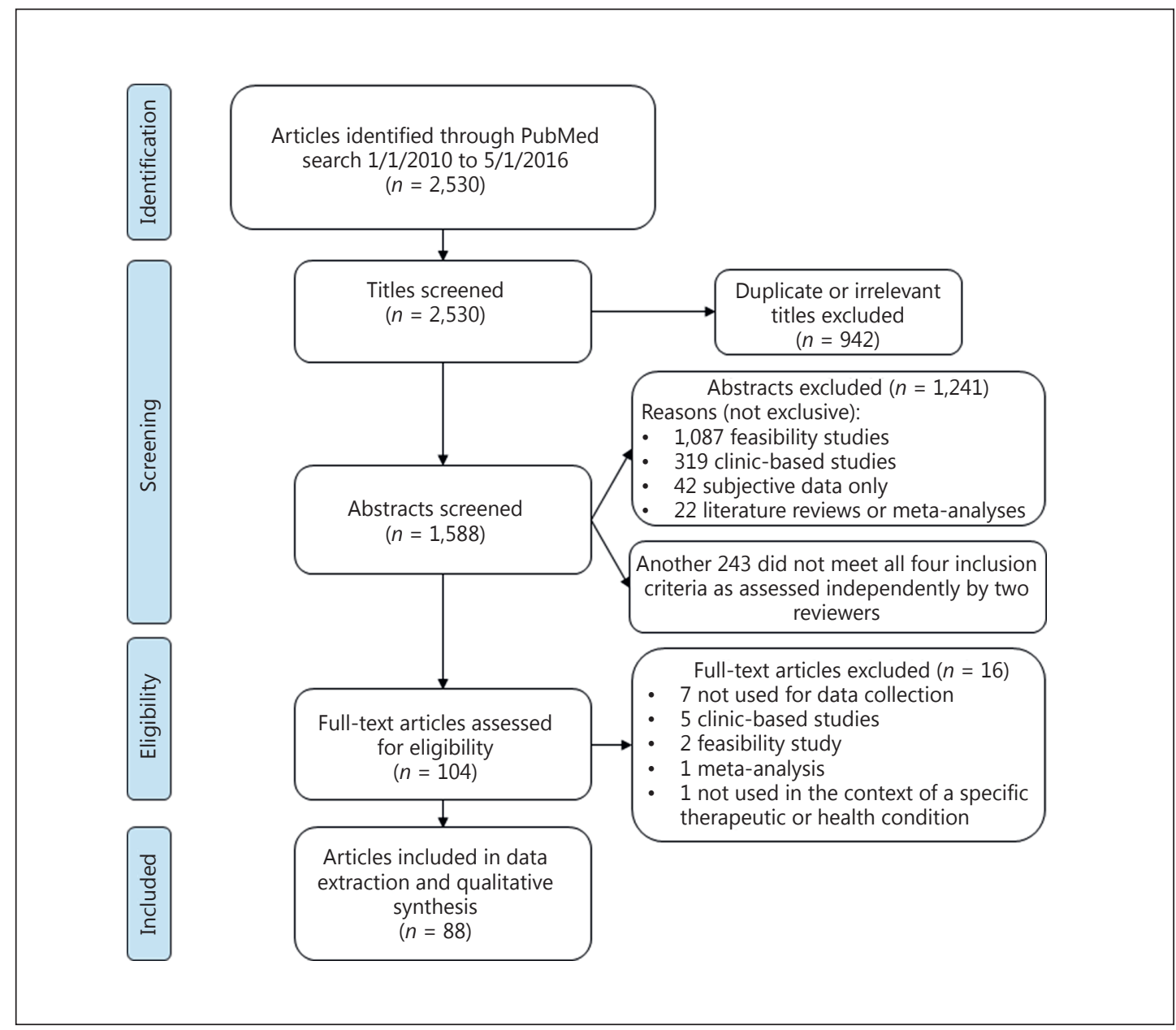

Fig. 1. Flow diagram of the review process.

research - e.g., whether the outcome was used as an assessment of users' physical activity, sleep, or respiration. Online supplementary materials for this publication summarize the context of use of the various mobile outcome assessments (for all online suppl. material, see www.karger.com/doi/10.1159/000486347).

\section{Results}

\section{Screening}

Our initial search (Appendix 1) retrieved 2,530 references (Fig. 1). We excluded just over a third of the retrieved publications $(n=942)$ after title screening and another $78 \%(n=$ $1,241)$ after abstract screening. The excluded publications predominately reported: (1) earlyphase studies of validity and reliability of the device or (2) clinic-based studies (i.e., wearable or sensor devices were not used for remote data capture). A total of 104 publications were included in the full document review. Upon further review, we excluded 16 additional publications on the basis of our inclusion and exclusion criteria. Data were extracted from the remaining 88 publications. 
Perry et al.: Use of Mobile Devices to Measure Outcomes in Clinical Research 2010-2016: A Systematic Literature Review

Table 1. Therapeutic areas and technologies by study design

\begin{tabular}{|c|c|c|c|c|}
\hline & \multicolumn{2}{|c|}{$\begin{array}{l}\text { Interventional trials } \\
(n=22)\end{array}$} & \multicolumn{2}{|c|}{$\begin{array}{l}\text { Observational studies } \\
(n=66)\end{array}$} \\
\hline & $n(\%)$ & Ref. & $n(\%)$ & Ref. \\
\hline \multicolumn{5}{|l|}{ Therapeutic area } \\
\hline Cardiology & $3(14)$ & $17,19,25$ & $16(24)$ & $31,37-40,53-63$ \\
\hline Diabetes & $5(28)$ & $11,12,24,26,28$ & $8(12)$ & $30,31,41,64-68$ \\
\hline Sleep & $3(14)$ & $15,20,21$ & $7(11)$ & $32,34-36,69-71$ \\
\hline Obesity & $0(0)$ & - & $9(14)$ & $30,72-79$ \\
\hline Geriatrics & $0(0)$ & - & 9 (14) & $80-88$ \\
\hline Neurology & $1(5)$ & 13 & $3(5)$ & $44,46,89$ \\
\hline Reproductive and peripartum health & $2(9)$ & 8,10 & $2(3)$ & 90,91 \\
\hline Orthopedics & $1(5)$ & 22 & $3(5)$ & $92-94$ \\
\hline Pulmonology & $0(0)$ & - & $3(5)$ & $95-97$ \\
\hline Arthritis & $1(5)$ & 16 & $2(3)$ & 93,98 \\
\hline Psychology & $0(0)$ & - & $3(5)$ & $78,99,100$ \\
\hline Cancer & $3(14)$ & $14,18,23$ & $0(0)$ & - \\
\hline Nephrology & $0(0)$ & - & $2(3)$ & 33,101 \\
\hline Gastroenterology & $1(5)$ & 29 & $1(2)$ & 43 \\
\hline Nutrition & $1(5)$ & 27 & $1(2)$ & 32 \\
\hline \multicolumn{5}{|l|}{ Device } \\
\hline Wearable inertial sensor/accelerometer & $16(73)$ & $8,9,12,14-25,27$ & $59(89)$ & $30,32-36,44,46,53-103$ \\
\hline Biosensor & $6(28)$ & $11,12,24,26,28,29$ & $7(11)$ & $31,33,37,39-41,43$ \\
\hline Continuous glucose monitor & $5(23)$ & $11,12,24,26,28$ & $1(2)$ & 41 \\
\hline Electrocardiograph & $0(0)$ & - & $2(3)$ & 31,40 \\
\hline Ingestible $\mathrm{pH}$ monitor & $1(5)$ & 29 & $1(2)$ & 43 \\
\hline Ambulatory blood pressure monitor & $0(0)$ & - & $1(2)$ & 39 \\
\hline Implantable cardioverter-defibrillator & $0(0)$ & - & $1(2)$ & 37 \\
\hline Heart rate monitor & $0(0)$ & - & $1(2)$ & 33 \\
\hline Pressure sensor and instrumented walkways & $1(5)$ & 13 & $1(2)$ & 38 \\
\hline Medication adherence monitor & $1(5)$ & 10 & $0(0)$ & - \\
\hline Geolocation monitor & $0(0)$ & - & $1(2)$ & 33 \\
\hline Global Positioning System & $0(0)$ & - & $1(2)$ & 33 \\
\hline Altimeter & $0(0)$ & - & $1(2)$ & 33 \\
\hline
\end{tabular}

\section{Data Extraction}

Only a quarter of the publications reviewed $(n=22 ; 25 \%)$ described interventional trials. All interventional trials were RCTs and included prevention trials $(n=5)$ [8-12], healthrelated quality-of-life trials $(n=11)$ [13-23] (which are RCTs that focus on managing the burden of chronic illness and coping with symptoms), and treatment trials $(n=6)$ [24-29] (which focus on assessing the safety and efficacy of a new medication or medical device). The remaining publications $(n=66)$ described observational clinical research studies where exposures were unassigned and outcomes were captured using mobile devices. The observational studies included epidemiological studies $(n=37)$, quality-of-life studies $(n=17)$, prevention studies $(n=6)$, diagnostic studies $(n=3), 1$ screening study, 1 genetic study, and 1 expanded access study (see online suppl. material Type and Design of Clinical Research Studies Using Mobile Outcome Assessments).

Thirteen different therapeutic areas were identified in the review (Table 1). The most frequently cited areas of study were cardiology $(n=19)$, diabetes $(n=13)$, sleep $(n=10)$, obesity $(n=9)$, and geriatrics $(n=9)$, all together comprising over half (68\%) of the 88 publications. These categories were not exclusive, as some studies investigated multiple related 
Perry et al.: Use of Mobile Devices to Measure Outcomes in Clinical Research,

2010-2016: A Systematic Literature Review

Table 2. Use of mobile outcome assessments in RCTs

\begin{tabular}{|c|c|c|c|c|c|c|c|c|c|c|}
\hline & \multicolumn{2}{|c|}{$\begin{array}{l}\text { Primary endpoint } \\
(n=10)\end{array}$} & \multicolumn{2}{|c|}{$\begin{array}{l}\text { Co-primary } \\
\text { endpoint }(n=5)\end{array}$} & \multicolumn{2}{|c|}{$\begin{array}{l}\text { Secondary endpoint } \\
(n=9)\end{array}$} & \multicolumn{2}{|c|}{$\begin{array}{l}\text { Exploratory } \\
\text { endpoint }(n=3)\end{array}$} & \multicolumn{2}{|c|}{ Other $(n=2)$} \\
\hline & $n(\%)$ & Ref. & $n(\%)$ & Ref. & $n(\%)$ & Ref. & $n(\%)$ & Ref. & $n(\%)$ & Ref. \\
\hline \multicolumn{11}{|l|}{ Therapeutic area } \\
\hline Cardiology & $1(10)$ & 19 & $1(20)$ & 17 & $2(22)$ & 19,25 & $0(0)$ & - & $0(0)$ & - \\
\hline Diabetes & $3(30)$ & $11,24,26$ & $2(40)$ & 12,28 & $3(33)$ & $11,26,28$ & $0(0)$ & - & $1(50)$ & 26 \\
\hline Sleep & $0(0)$ & - & $1(20)$ & 21 & $2(22)$ & 15,20 & $0(0)$ & - & $0(0)$ & - \\
\hline Neurology & $1(10)$ & 13 & $0(0)$ & - & $0(0)$ & - & $0(0)$ & - & $0(0)$ & - \\
\hline $\begin{array}{l}\text { Reproductive and } \\
\text { peripartum health }\end{array}$ & $2(20)$ & 8,10 & $0(0)$ & - & $0(0)$ & - & $0(0)$ & - & $0(0)$ & - \\
\hline Orthopedics & $1(10)$ & 22 & $0(0)$ & - & $1(11)$ & 22 & $0(0)$ & - & $0(0)$ & - \\
\hline Pediatrics & $0(0)$ & - & $0(0)$ & - & $0(0)$ & - & $1(33)$ & 9 & $0(0)$ & - \\
\hline Arthritis & $0(0)$ & - & $0(0)$ & - & $1(11)$ & 16 & $0(0)$ & - & $0(0)$ & - \\
\hline Cancer & $0(0)$ & - & $1(20)$ & 23 & $0(0)$ & - & $2(66)$ & 14,18 & $1(50)$ & 14 \\
\hline Gastroenterology & $1(10)$ & 29 & $0(0)$ & - & $0(0)$ & - & $0(0)$ & - & $0(0)$ & - \\
\hline Nutrition & $1(10)$ & 27 & $0(0)$ & - & $0(0)$ & - & $0(0)$ & - & $0(0)$ & - \\
\hline \multicolumn{11}{|l|}{ Mobile outcome category } \\
\hline Performance outcome & $6(60)$ & $\begin{array}{l}8,10,13,19,22, \\
27\end{array}$ & $3(60)$ & $17,21,23$ & $6(67)$ & $\begin{array}{l}15,16,19,20 \\
22,25\end{array}$ & $3(100)$ & $\begin{array}{l}9,14 \\
18\end{array}$ & $1(50)$ & 14 \\
\hline Biomarkers & $4(40)$ & $11,24,26,29$ & $2(40)$ & 12,28 & $3(33)$ & $11,26,28$ & $0(0)$ & & $1(50)$ & 26 \\
\hline \multicolumn{11}{|l|}{ Device } \\
\hline $\begin{array}{l}\text { Wearable inertial sensor/ } \\
\text { accelerometer }\end{array}$ & $5(50)$ & $8,19,22,24,27$ & $4(80)$ & $\begin{array}{l}12,17 \\
21,23\end{array}$ & $6(67)$ & $\begin{array}{l}15,16,19,20 \\
22,25\end{array}$ & $3(100)$ & $\begin{array}{l}9,14 \\
18\end{array}$ & $1(50)$ & 14 \\
\hline Biosensor & $4(40)$ & $11,24,26,29$ & $2(40)$ & 12,28 & $3(33)$ & $11,26,28$ & $0(0)$ & - & $1(50)$ & 26 \\
\hline Continuous glucose monitor & $3(30)$ & $11,24,26$ & $2(40)$ & 12,28 & $3(33)$ & $11,26,28$ & $0(0)$ & - & $1(50)$ & 26 \\
\hline Ingestible $\mathrm{pH}$ monitor & $1(10)$ & 29 & $0(0)$ & - & $0(0)$ & - & $0(0)$ & - & $0(0)$ & - \\
\hline $\begin{array}{l}\text { Pressure sensor and } \\
\quad \text { instrumented walkways }\end{array}$ & $1(10)$ & 13 & $0(0)$ & - & $0(0)$ & - & $0(0)$ & - & $0(0)$ & - \\
\hline Medication adherence monitor & $1(10)$ & 10 & $0(0)$ & - & $0(0)$ & - & $0(0)$ & - & $0(0)$ & - \\
\hline
\end{tabular}

therapeutic areas (e.g., diabetes and obesity [30], diabetes and myocardial infarctions [31], nutrient deficiency and sleep [32]).

Five different mobile device categories were identified (Table 1). The overwhelming majority of the publications $(86 \% ; n=75)$ used inertial (motion) sensors to capture mobile outcomes. Inertial sensors include accelerometers and gyroscopes and are used to measure a body's acceleration and angular rate of motion. Biosensors were the next most common type of device identified $(15 \% ; n=13)$. These included continuous glucose monitors (CGMs), ambulatory electrocardiographs, ingestible $\mathrm{pH}$ monitors, ambulatory blood pressure monitors, implantable cardioverter defibrillators, and heart rate monitors. Other mobile devices used were pressure sensors and instrumented walkways, medication adherence monitors, and geolocation monitors. Some studies used multiple devices to measure outcomes (e.g., a CGM and accelerometer [12, 24], a heart rate monitor and accelerometer with geolocation monitoring [33]).

Two types of mobile outcome were identified in the publications: mobile performance outcomes and biomarkers. Mobile outcomes were often captured multiple times per day and in free-living conditions. The most common were mobile performance outcomes of users' physical activity, which were identified in $74 \%$ of the publications $(n=65)$. Other mobile performance outcomes included measurements of users' sleep, mobility, and pill adherence. Mobile biomarkers included measures of cardiac, glucose, gastric reflux, and respiration outcomes, as well as the intensity of head-related injury. Mobile outcome measurements were used in 15 publications to assess primary or co-primary endpoints in RCTs (Table 2). In each of these studies, other conventionally measured outcome assessments, including observed and self-reported outcome measures, were captured. 
Table 3. Mobile PA outcomes

\begin{tabular}{|c|c|c|c|}
\hline Mobile outcomes & $\begin{array}{l}\text { RCTs } \\
(n=13), \\
n(\%)\end{array}$ & $\begin{array}{l}\text { Observational } \\
\text { studies } \\
(n=52), n(\%)\end{array}$ & $\begin{array}{l}\text { Total } \\
\text { publications } \\
(n=65), n(\%)\end{array}$ \\
\hline Intensity & $9(69)$ & 40 (77) & $49(75)$ \\
\hline Accelerometer counts & $6(46)$ & $23(44)$ & $29(45)$ \\
\hline Average counts per day & $6(46)$ & $22(42)$ & $28(43)$ \\
\hline Total counts per day & $0(0)$ & $2(4)$ & $2(3)$ \\
\hline Average counts between symptom reporting & $1(8)$ & $0(0)$ & $1(2)$ \\
\hline Average counts during data collection period & $1(8)$ & $0(0)$ & $1(2)$ \\
\hline Step counts & $1(8)$ & $20(38)$ & $21(32)$ \\
\hline Average daily step count & $0(0)$ & $16(31)$ & $16(25)$ \\
\hline Total steps per data collection period & $1(8)$ & $3(6)$ & $4(6)$ \\
\hline Average steps per bout of continuous steps & $0(0)$ & $3(6)$ & $3(5)$ \\
\hline Cadence (steps per minute) & $0(0)$ & $2(4)$ & $2(3)$ \\
\hline METs & $0(0)$ & $10(19)$ & $10(15)$ \\
\hline METs per minute & $0(0)$ & 9 (17) & $9(14)$ \\
\hline METs per sustained bout of MVPA (>10 min) & $0(0)$ & $2(4)$ & $2(3)$ \\
\hline METs per hour & $0(0)$ & $1(2)$ & $1(2)$ \\
\hline Daily caloric (energy) expenditure (kcal per day) & $2(15)$ & $7(13)$ & $9(14)$ \\
\hline $\begin{array}{l}\text { Daily peak and low activity counts and ratios (e.g., 1- and 2-h peak counts per day, } \\
\text { sedentary-to-light activity ratio) }\end{array}$ & $0(0)$ & $7(13)$ & $7(11)$ \\
\hline Duration & $6(46)$ & $39(75)$ & $45(69)$ \\
\hline Minutes per day of activity of varying intensity & $4(31)$ & $32(62)$ & $36(55)$ \\
\hline Minutes per day of MVPA & $4(31)$ & $29(56)$ & $33(51)$ \\
\hline Minutes per day sedentary & $2(15)$ & $24(46)$ & $26(40)$ \\
\hline Minutes per day of light intensity & $2(15)$ & $19(37)$ & $21(32)$ \\
\hline Minutes per day of all intensity & $2(15)$ & $9(17)$ & $11(17)$ \\
\hline Minutes per bout of MVPA & $0(0)$ & $8(15)$ & $8(12)$ \\
\hline $\begin{array}{l}\text { Minutes per day doing various activities (e.g., lying down, sitting, standing, } \\
\text { moving, shuffling, walking) }\end{array}$ & $1(8)$ & $5(10)$ & $6(9)$ \\
\hline Cumulative daily minutes per bout of sedentariness & $1(8)$ & $3(6)$ & $4(6)$ \\
\hline Percent of daily time doing various activities (e.g., wearing device; inactivity; & & & \\
\hline sitting; low, medium, high step activity) & $0(0)$ & $3(6)$ & $3(5)$ \\
\hline Percent of daily time in sustained (e.g., $>1 \mathrm{~min}, \geq 10 \mathrm{~min}$ ) MVPA & $0(0)$ & $1(2)$ & $1(2)$ \\
\hline Cumulative daily minutes per bout (lasting $1 \mathrm{~h}$ or more) of MVPA & $0(0)$ & $1(2)$ & $1(2)$ \\
\hline Frequency & $1(8)$ & $14(27)$ & $15(23)$ \\
\hline Number of daily bouts of varying activity & $1(8)$ & $10(19)$ & $11(17)$ \\
\hline Number of moderate- or vigorous-intensity bouts & $0(0)$ & $4(8)$ & $4(6)$ \\
\hline Number of daily sedentary bouts of varying duration (e.g., $\leq 30,>30,>60 \mathrm{~min}$ ) & $0(0)$ & $3(6)$ & $3(5)$ \\
\hline Number of sedentary breaks & $0(0)$ & $3(6)$ & $3(5)$ \\
\hline Number of sit-to-stand transitions & $0(0)$ & $2(4)$ & $2(3)$ \\
\hline Number of walking bouts of varying intensity & $0(0)$ & $2(4)$ & $2(3)$ \\
\hline Number of daily upright events & $1(8)$ & $0(0)$ & $1(2)$ \\
\hline Description of physical activity patterns & $0(0)$ & $3(6)$ & $3(5)$ \\
\hline Intermittent or real-world nature of activity intensity & $0(0)$ & $1(2)$ & $1(2)$ \\
\hline Staggering of daily physical activity (1- and 2-h peak-to-average-activity counts) & $0(0)$ & $1(2)$ & $1(2)$ \\
\hline Diurnal profile of physical activity (average steps per hour across different times of day) & $0(0)$ & $1(2)$ & $1(2)$ \\
\hline Variance of time between bouts & $0(0)$ & $1(2)$ & $1(2)$ \\
\hline Other physical activity endpoints & $0(0)$ & $6(12)$ & $6(9)$ \\
\hline Proportion of population meeting guidelines & $0(0)$ & $6(12)$ & $6(9)$ \\
\hline Healthy People 2010 PA recommendations & $0(0)$ & $1(2)$ & $1(2)$ \\
\hline 2010 WHO guidelines (achieving at least $2.5 \mathrm{~h}$ of MVPA per week) & $0(0)$ & $1(2)$ & $1(2)$ \\
\hline WHO recommendations (average of $\geq 60 \mathrm{~min}$ of MVPA per day) & $0(0)$ & $1(2)$ & $1(2)$ \\
\hline UK PA Guidelines & $0(0)$ & $1(2)$ & $1(2)$ \\
\hline ACSM higher limit recommendation for PA & $0(0)$ & $1(2)$ & $1(2)$ \\
\hline ACSM lower limit recommendation for PA (67 METs min a day) & $0(0)$ & $1(2)$ & $1(2)$ \\
\hline AHA and ACSM minimum recommendations of PA & $0(0)$ & $1(2)$ & $1(2)$ \\
\hline National Association for Sport and Physical Education PA recommendations & $0(0)$ & $1(2)$ & $1(2)$ \\
\hline
\end{tabular}

PA, physical activity; METs, metabolic equivalents; MVPA, moderate-to-vigorous PA; ACSM, American College of Sports Medicine; AHA, American Heart Association. 
Perry et al.: Use of Mobile Devices to Measure Outcomes in Clinical Research, 2010-2016: A Systematic Literature Review

\section{Mobile Performance Outcomes}

Physical Activity

Mobile outcome assessments of physical activity included measurements of device users' activity intensity, duration, and frequency (Table 3). Each of these assessments used inertial sensors, although these devices were used in a variety of study contexts (see online suppl. Table Mobile Physical Activity Outcomes). The placement of wearable devices on users' bodies was dependent on the device and intended physical activity; however, over half ( $n=$ 38) of the publications reporting physical activity-related outcomes noted using waist-worn devices (see online suppl. Table Mobile Physical Activity Outcomes for a full list of device placements for various physical activity assessments). Wearable inertial sensors were also placed on users' wrist, leg, foot, arm, base of the spine, and head. Of the publications that specified the frequency with which mobile physical activity outcomes were collected $(n=22)$, over half $(n=12)$ sampled in 60 -s epochs (see online suppl. Table Mobile Physical Activity Outcomes for a full list of sampling frequencies reported). Thirteen publications described the use of mobile devices to collect objective physical activity data in RCTs, and 52 publications described their use in observational studies (see online suppl. material Use of Mobile Outcomes in Clinical Research).

Among the RCTs, mobile physical activity outcomes were used in a wide range of study contexts. For example, they were used in quality-of-life RCTs among patients with arthritis [16], cancer [14, 18, 23], various forms of heart disease [17, 19], Parkinson's disease [13], hip fractures [22], and insomnia [20]. Other RCTs included 2 prevention trials to increase physical activity among adolescents [9] and postpartum women [8], 1 phase II trial of a counseling intervention to reduce sedentary time among stroke survivors [25], and 1 phase III trial of the effects of nutrient supplements among 18-month-old children [27]. The mobile physical activity outcomes were used as primary or co-primary endpoints in 7 of these trials, as secondary endpoints in 4 trials, and as exploratory endpoints in 3 trials (Table 2).

Similarly, a wide range of observational studies used mobile outcomes of physical activity. A list of these studies and the context of use of the mobile outcomes measured can be found in the online supplementary material (online suppl. Table Mobile Physical Activity Outcomes).

Sleep

Mobile outcomes of participants' sleep performance included measurements of duration of rest, sleep efficiency (i.e., percent of time in bed spent sleeping), wakefulness after sleep onset, sleep latency (i.e., the amount of time after recorded bedtime and sleep onset), and personal light exposure (Table 4). Three publications reported the use of mobile sleep outcomes in RCTs, while another 8 publications reported mobile sleep outcomes in observational studies (see online suppl. material Use of Mobile Outcomes in Clinical Research).

The 3 RCTs were all quality-of-life studies that assessed the impact of an intervention on participants' sleep quality. The participants in 2 of these RCTs wore Actiwatch devices (Philips Respironics, Bend, OR, USA) on their wrists $[15,21]$, while the participants in the other RCT wore a SenseWear Armband (SensorMedics Italia, Milan, Italy) placed on their nondominant upper arm [20]. In 1 of the RCTs, the Actiwatch device was used to measure users' sleep performance as a co-primary study endpoint [21] (Table 2). In the other 2 RCTs, mobile sleep outcomes were used to assess secondary endpoints $[15,20]$ (Table 2). See online supplementary Table Mobile Sleep Outcomes for a full list of observational studies.

Inertial sensors were used in the majority of sleep-related observational studies to measure sleep quality, and their outcomes were compared or combined with conventional measurements of sleep, including self-reported and direct observation (see online suppl. Table Mobile Sleep Outcomes). One study, however, compared a standard biomarker for sleep outcome (i.e., levels of melatonin in saliva samples) to a mobile sleep outcome using 
Table 4. Mobile sleep outcomes

\begin{tabular}{|c|c|c|c|}
\hline Mobile outcomes & $\begin{array}{l}\text { RCTs } \\
(n=3), \\
n(\%)\end{array}$ & $\begin{array}{l}\text { Observational } \\
\text { studies } \\
(n=8), n(\%)\end{array}$ & $\begin{array}{l}\text { Total } \\
\text { publications } \\
(n=11), n(\%)\end{array}$ \\
\hline Duration of rest & $3(100)$ & $7(88)$ & $10(91)$ \\
\hline Total sleep time & $3(100)$ & $3(38)$ & $6(55)$ \\
\hline Total time in bed & $2(67)$ & $0(0)$ & $2(18)$ \\
\hline Bed time & $1(33)$ & $0(0)$ & $1(9)$ \\
\hline Average nap time & $0(0)$ & $1(13)$ & $1(9)$ \\
\hline Sleep period time & $0(0)$ & $1(13)$ & $1(9)$ \\
\hline Longest sleep period & $0(0)$ & $1(13)$ & $1(9)$ \\
\hline True sleep time & $0(0)$ & $1(13)$ & $1(9)$ \\
\hline Sleep duration & $0(0)$ & $1(13)$ & $1(9)$ \\
\hline Hours with rapid shallow breathing & $0(0)$ & $1(13)$ & $1(9)$ \\
\hline Time asleep & $0(0)$ & $1(13)$ & $1(9)$ \\
\hline \multicolumn{4}{|l|}{ Sleep efficiency percentage (e.g., actual sleep } \\
\hline time/total sleep duration or time in bed) & $2(67)$ & $4(50)$ & $6(55)$ \\
\hline Wakefulness after sleep onset & $1(33)$ & $5(63)$ & $6(55)$ \\
\hline Time awake after sleep onset & $1(33)$ & $4(50)$ & $5(45)$ \\
\hline Number of awakenings after sleep onset & $0(0)$ & $3(38)$ & $3(27)$ \\
\hline Sleep onset latency & $2(67)$ & $2(25)$ & $5(36)$ \\
\hline Activity level during sleep & $0(0)$ & $2(25)$ & $2(18)$ \\
\hline Sleep activity level & $0(0)$ & $1(13)$ & $1(9)$ \\
\hline Movement rate & $0(0)$ & $1(13)$ & $1(9)$ \\
\hline Standard deviation of movement rate & $0(0)$ & $1(13)$ & $1(9)$ \\
\hline Patterns of behavior during sleep & $0(0)$ & $1(13)$ & $1(9)$ \\
\hline Personal light exposure & $0(0)$ & $1(13)$ & $1(9)$ \\
\hline Circadian illuminance & $0(0)$ & $1(13)$ & $1(9)$ \\
\hline Photopic illuminance & $0(0)$ & $1(13)$ & $1(9)$ \\
\hline Circadian stimulus & $0(0)$ & $1(13)$ & $1(9)$ \\
\hline
\end{tabular}

the Daysimeter-D inertial sensor (Lighting Research Center, Troy, NY, USA) [34]. The Daysimeter-D is a small device that combines inertial sensing and a light meter to measure ambient levels of light. The participants in this study wore goggles mounted with the Daysimeter-D device to measure activity as well as light exposure [34]. The wearable devices used in other observational studies measuring sleep were primarily placed on the users' nondominant wrist or arm. Children in 1 observational study wore the ActiGraph GT3X+ accelerometer (ActiGraph, Pensacola, FL, USA) on their waists to collect daytime as well as sleep-time activity [35]. Mobile outcomes measuring sleep performance were used to measure primary or co-primary study endpoints in 3 of these observational studies [32, 35, 36]. A full list of how these outcomes were used can be found in online supplementary Table Mobile Sleep Outcomes.

Mobility

Assessment of mobile device users' mobility included objective measurements of gross motor activity, including walking speed, upright time, and quality of gait (Table 5). Two publications reported mobile performance outcomes of users' mobility in RCTs, and 3 other publications reported their use in observational studies (see online suppl. Table Mobile Mobility Outcomes). The 2 RCTs were both quality-of-life studies. In one of these RCTs, patients with Parkinson's disease used a wearable inertial sensor (CuPiD system) placed on their ankles and a portable, pressure-sensing, instrumented walkway placed on the floor (PKMAS 
Perry et al:: Use of Mobile Devices to Measure Outcomes in Clinical Research, 2010-2016: A Systematic Literature Review

Table 5. Mobile mobility outcomes

\begin{tabular}{llll}
\hline Mobile outcomes & $\begin{array}{l}\text { RCTs } \\
(n=2), n(\%)\end{array}$ & $\begin{array}{l}\text { Observational } \\
\text { studies }(n=3), n(\%)\end{array}$ & $\begin{array}{l}\text { Total publications } \\
(n=5), n(\%)\end{array}$ \\
\hline Walking speed & $1(50)$ & $2(67)$ & $3(60)$ \\
Upright time (standing and walking) over $24 \mathrm{~h}$ & $1(50)$ & $0(0)$ & $1(20)$ \\
Gait quality & $0(0)$ & $1(33)$ & $1(20)$ \\
$\quad$ Smoothness of gait & $0(0)$ & $1(33)$ & $1(20)$ \\
$\quad$ Stride regularity (gait rhythm and consistency) & $0(0)$ & $1(33)$ & $1(20)$ \\
$\quad$ Width of dominant peak in power spectrum & $0(0)$ & $1(20)$ \\
\hline
\end{tabular}

Walkway; ProtoKinetics, Havertown, PA, USA) to assess a primary endpoint [13] (Table 2). In the other RCT, geriatric patients used inertial sensors (activPAL; PAL Technologies Ltd., Glasgow, UK) placed on their thigh after surgery for hip fractures to assess a secondary endpoint [22]. See online suppl. Table Mobile Mobility Outcomes for more information on the placement of mobile devices to assess mobility performance and for information on observational studies using mobile outcome assessments of mobility.

Adherence

One publication [10] reported an RCT using a mobile medication adherence monitor (SIMpill ${ }^{\circledR}$, London, UK) to assess the mean number of pills missed as a means of measuring patient adherence to an oral contraceptive pill (see suppl. Table Mobile Adherence Outcomes for a list of contexts of use). The adherence monitor is an electronic pillbox that records the time and date of accessing the pills contained within the device. The study, which investigated the impact of daily text message reminders on contraceptive pill adherence, used the mobile outcome to assess the study's primary endpoint.

\section{Mobile Biomarkers}

Cardiac Biomarkers

Mobile assessment of cardiac biomarkers included continuous monitoring and measurement of patients' heart rate, daytime and nighttime pulse pressure, occurrence of atrial fibrillation, heart rate turbulence, and T-wave analyses (Table 6). All of the publications reporting on the use of mobile cardiac biomarkers were observational and included epidemiological $(n=2)$, prevention $(n=2)$, diagnostic $(n=1)$, and genetic $(n=1)$ studies. Devices used included ambulatory heart rate monitors, electrocardiographs, ambulatory blood pressure monitor, implantable cardioverter-defibrillators, and pressure sensors. Mobile cardiac biomarkers were used to measure study outcomes among patients with atrial fibrillation [37], heart failure [38], hypertension [39], and myocardial infarctions [31], as well as patients who had undergone kidney transplant surgery [33]. The mobile cardiac biomarkers were used to measure either primary or co-primary study endpoints in 4 observational studies [33, 37, 39, 40] and exploratory endpoints in 2 observational studies [31, 38] (see online suppl. Table Mobile Cardiac Biomarkers for a list of contexts of use of cardiac biomarkers).

\section{Glucose Biomarkers}

Mobile biomarkers of users' glucose were measured by continuous glucose monitoring using wearable CGMs. Mobile biomarkers included remote monitoring of average glucose 
Table 6. Mobile cardiac biomarkers

\begin{tabular}{|c|c|c|c|}
\hline Mobile outcomes & $\begin{array}{l}\text { RCTs } \\
(n=0), n(\%)\end{array}$ & $\begin{array}{l}\text { Observational } \\
\text { studies }(n=6), n(\%)\end{array}$ & $\begin{array}{l}\text { Total publications } \\
(n=6), n(\%)\end{array}$ \\
\hline Heart rate $(\mathrm{bpm})$ & $0(0)$ & $3(50)$ & $3(50)$ \\
\hline Standard deviation of heart rate & $0(0)$ & $1(17)$ & $1(17)$ \\
\hline Daytime pulse pressure (mm Hg) & $0(0)$ & $1(17)$ & 1 (17) \\
\hline Nighttime pulse pressure (mm Hg) & $0(0)$ & $1(17)$ & 1 (17) \\
\hline Occurrence of atrial fibrillation (for $>6 \mathrm{~min}$ or $6 \mathrm{~h}$ ) & $0(0)$ & $1(17)$ & $1(17)$ \\
\hline Heart rate turbulence & $0(0)$ & $1(17)$ & 1 (17) \\
\hline Turbulence onset & $0(0)$ & $1(17)$ & 1 (17) \\
\hline Turbulence slope & $0(0)$ & $1(17)$ & $1(17)$ \\
\hline T-wave analyses & $0(0)$ & $1(17)$ & 1 (17) \\
\hline QT interval & $0(0)$ & $1(17)$ & $1(17)$ \\
\hline \multicolumn{4}{|l|}{ Fully automatic biomarkers of the $\mathrm{T}$ wave named } \\
\hline biGaussian function & $0(0)$ & $1(17)$ & $1(17)$ \\
\hline \multicolumn{4}{|l|}{ 3D markers derived from a principal component } \\
\hline analysis on the $\mathrm{T}$ wave & $0(0)$ & $1(17)$ & 1 (17) \\
\hline
\end{tabular}

bpm, beats per minute.

Table 7. Mobile glucose biomarkers

\begin{tabular}{|c|c|c|c|}
\hline Mobile outcomes & $\begin{array}{l}\text { RCTs } \\
(n=5), \\
n(\%)\end{array}$ & $\begin{array}{l}\text { Observational } \\
\text { studies }(n=1) \text {, } \\
n(\%)\end{array}$ & $\begin{array}{l}\text { Total } \\
\text { publications } \\
(n=6), n(\%)\end{array}$ \\
\hline Average glucose level & $5(100)$ & $1(100)$ & $6(100)$ \\
\hline Mean glucose level as measured with the use of CGMs & $4(80)$ & $1(100)$ & $5(83)$ \\
\hline Median glucose level & $1(20)$ & $0(0)$ & $1(17)$ \\
\hline Time in range & $4(80)$ & $1(100)$ & $5(83)$ \\
\hline \multicolumn{4}{|l|}{ Percentage of time in "normal" blood glucose range } \\
\hline$(3.9-10 \mathrm{mmol} / \mathrm{L}$ or $70-180 \mathrm{mg} / \mathrm{dL})$ & $4(80)$ & $1(100)$ & $5(83)$ \\
\hline Over $24 \mathrm{~h}$ & $3(60)$ & $1(100)$ & $4(67)$ \\
\hline During nighttime and evening hours & $1(20)$ & $0(0)$ & $1(17)$ \\
\hline During intervention period & $1(20)$ & $0(0)$ & $1(17)$ \\
\hline \multicolumn{4}{|l|}{ Percentage of time spent in hyperglycemic range } \\
\hline (>10 mmol/L or $180 \mathrm{mg} / \mathrm{dL})$ & $3(60)$ & $1(100)$ & $4(67)$ \\
\hline \multicolumn{4}{|l|}{ Percentage of time spent in hypoglycemic range } \\
\hline$(<3.9 \mathrm{mmol} / \mathrm{L}$ or $70 \mathrm{mg} / \mathrm{dL})$ & $3(60)$ & $1(100)$ & $4(67)$ \\
\hline Mean percent of time with a low glucose level & $1(20)$ & $0(0)$ & $1(17)$ \\
\hline Time in tight glucose target range $(4.4-7.8 \mathrm{mmol} / \mathrm{L})$ & $1(20)$ & $0(0)$ & 1 (17) \\
\hline \multicolumn{4}{|l|}{ Percentage of time spent in severe hypoglycemic } \\
\hline range $(<55 \mathrm{mg} / \mathrm{dL})$ & $1(20)$ & $0(0)$ & $1(17)$ \\
\hline \multicolumn{4}{|l|}{ Percentage of time in mild hyperglycemic range } \\
\hline$(180-250 \mathrm{mg} / \mathrm{dL})$ & $1(20)$ & $0(0)$ & $1(17)$ \\
\hline Number of episodes of severe hypoglycemia & $2(40)$ & $1(100)$ & $3(50)$ \\
\hline Glucose level variability & $2(40)$ & $1(100)$ & $3(50)$ \\
\hline Standard deviation of blood glucose & $2(40)$ & $1(100)$ & $3(50)$ \\
\hline Minimum and maximum glycemic values & $1(20)$ & $0(0)$ & $1(17)$ \\
\hline
\end{tabular}

CGMs, continuous glucose monitors. 
Table 8. Mobile gastric reflux biomarkers

\begin{tabular}{llll}
\hline Mobile outcomes & $\begin{array}{l}\text { RCTs } \\
(n=1), n(\%)\end{array}$ & $\begin{array}{l}\text { Observational } \\
\text { studies }(n=1), n(\%)\end{array}$ & $\begin{array}{l}\text { Total publications } \\
(n=2), n(\%)\end{array}$ \\
\hline $\begin{array}{l}\text { Percent of total time with a pH }<4 \text { over } \\
\text { various time periods }(24 \mathrm{~h}, 48 \mathrm{~h})\end{array}$ & $1(100)$ & $1(100)$ & $2(100)$ \\
$\begin{array}{l}\text { DeMeester score } \\
\text { Total number of acid episodes }\end{array}$ & $1(100)$ & $1(100)$ & $2(100)$ \\
$1(50)$
\end{tabular}

levels, as well as the time in range, number of severe hypoglycemic episodes, glucose level variability, and minimum and maximum glycemic values (Table 7). Mobile glucose biomarkers were used as primary outcomes in 5 RCTs (Table 2). Each of the RCTs assessed the use of closed-loop sensor-augmented insulin pump therapies - or artificial pancreases - to manage glycemic variability and reduce the time outside of the "normal" glucose range among patients with type 1 diabetes. Mobile glucose biomarkers were also used to measure secondary study endpoints in 3 other trials (Table 2) and 1 observational study [41]. See online supplementary Table Mobile Glucose Biomarkers for a full list of contexts of use of glucose biomarkers.

Gastric Reflux Biomarkers

Mobile outcomes of gastric reflux biomarkers included continuous real-world monitoring and measurement of the percent of time with a gastric $\mathrm{pH}<4$, the users' DeMeester score [42], and the total number of acid episodes (Table 8). One publication reported the use of mobile gastric reflux biomarkers in a phase IV RCT investigating appropriate treatment dosing [29], and another publication reported their use in an observational study investigating the diagnosis of gastroesophageal reflux disease [43]. Both of these studies used the Bravo $\mathrm{pH}$ capsule monitoring device (Medtronic, Minneapolis, MN, USA), which was attached to the patients' esophageal mucosa by a clinician. The observational study reported sampling users' pH levels every 6 s [43]. The online supplementary Table Mobile Gastric Reflux Biomarkers provides more details on the contexts of use of these mobile outcomes.

Respiration Biomarkers

One publication reported measuring mobile outcomes of respiration, including the rate and standard deviation of respiration, by placing a pressure sensor under patients' mattresses (see online suppl. Table Mobile Respiration Biomarkers) [38]. This mobile biomarker was incorporated as an exploratory endpoint in an observational cardiology study to assess physiological patterns of patients with heart failure in the home environment and to determine if specific patterns correlate with hospital readmissions [38].

Intensity of Head-Related Injury Biomarkers

One publication [44] used an inertial sensor (X2 Biosystems Inc., Seattle, WA, USA) placed in the mouth guard of rugby players to measure the magnitude and frequency of head impacts. Specific measurements included the linear and rotational acceleration of the head after impact, impact location, and frequency and duration (measured in milliseconds) of the impact (see online suppl. Table Mobile Head-Related Injury Intensity Biomarkers for further information on the context of use) sampled at 1,000 $\mathrm{Hz}$ (i.e., 1,000 times per second). Response biomarkers [3] were interpreted from the exposure (i.e., head impact) measures using previously published thresholds for injury tolerance levels for concussion, total impact frequency burden, and head impact severity. 


\section{Discussion}

This systematic review describes recent use of mobile devices in clinical research. We found that mobile devices are being used across a variety of therapeutic areas, but they are currently more commonly used in observational than interventional research. Because the use of mobile devices in any type of clinical research can inform how these devices could be used in future interventional research, we have chosen to include information about their use in observational research in this review.

The majority of publications reported using mobile outcomes - including continuous and remote monitoring of users' performance and specific biomarkers - to inform primary or co-primary study endpoints. Mobile devices provided new ways to assess clinical outcomes and biomarkers at higher frequency, outside of structured research settings, during activities of daily living, and with greater objectivity, given the technologies' ability to monitor patients with minimal self- or observer input. The uses of inertial sensors/accelerometers were reported in a large proportion of the reviewed publications to remotely capture users' physical activity, sleep, and mobility.

Given the broad scope of our search terms, we identified and summarized a variety of mobile biomarkers (e.g., continuous glucose monitoring, ambulatory blood pressure monitoring, continuous $\mathrm{pH}$ monitoring). In the publications we reviewed, the biomarkers may have also had multiple applications in the clinical studies. For instance, they may have been used for prognostic or predictive purposes and/or for monitoring safety [3]. During this review, we noted that applying current definitions for conventionally measured outcomes to mobile outcomes was difficult, as current category definitions [2, 3] may not adequately reflect the novelty of mobile outcome assessments. Biomarkers are currently defined as assessments of biological processes, such as histological, biochemical, or radiographic measurements, that reflect the physiological effects of disease progression or therapeutic intervention. It is often noted that they are not direct assessments of how a patient feels, functions, or survives [2, 3, 45]. Other clinical outcome assessments, including clinician-reported outcomes, observer-reported outcomes, PROs, and performance outcomes, can provide more direct assessment of meaningful health aspects [2]. Performance outcomes are quantifications of patient performance in a specified task instructed by a health care professional, while each of the other outcome assessments are based upon observations originating from specific observers, i.e., health care professionals, patients, or someone other than the patient or a health care professional [3]. Unfortunately, these definitions do not take into account the novelty of mobile device-based measurements, which include measurements collected while users engage in activities related to their daily living without researcher supervision, nor the high frequency of data capture of mobile sensors, some of which have the capability of sampling at several hundred times per second - rates that for all intents and purposes may be considered "continuous" during the measurement epoch. It is likely that, by objectively measuring day-to-day patient activity and more acute fluctuations in biological markers, mobile outcomes may be able to more directly assess meaningful patient health outcomes and thus provide a more complete overall picture of disease burden and therapeutic effect. For the purposes of this review, we placed mobile outcomes into existing categories for purposes of comparison; however, it may be necessary to include new categories (or modify current definitions) of clinical outcome assessments in order to accommodate novel measures using mobile devices and advance their use in interventional research.

Another factor that may be hindering the use of mobile devices in interventional research is the lack of standardization. We found that studies investigated a wide range of variables within specific mobile outcomes. As an example, studies included in our review captured a wide variety of mobile performance outcomes used to measure the intensity, duration, and 
Perry et al.: Use of Mobile Devices to Measure Outcomes in Clinical Research, 2010-2016: A Systematic Literature Review

frequency of users' physical activity. Further, studies used an array of variables to assess their endpoints, including variations in sampling rates, placement of the device, and technologies. In particular, there is a wide array of inertial sensors on the market that have varying proprietary standards for reporting physical activity outcomes. If this trend continues, the lack of standardization will make interpreting and comparing results across studies and across therapeutic areas more difficult, thereby inhibiting the acceptance and greater use of mobile outcomes in regulatory interventional research.

In our review we did not attempt to identify the intended use of specific biomarkers (e.g., prognostic biomarkers, predictive biomarkers, or safety biomarkers [3]) but recognize that not all biomarkers are used ultimately to assess research outcomes. Identifying the intended use of these measurements would provide greater understanding of how to appropriately use them in clinical research. Additionally, in identifying and categorizing mobile outcomes in clinical research, we attempted to only identify measurements used to assess a clinical outcome (e.g., severity of head impact), rather than to measure an exposure (e.g., frequency of head impacts). However, given the variety of new technologies used in clinical research, this can be difficult to distinguish. For example, some technologies have the capability of capturing a wide range of data at one time, including data that could be used to identify exposures as well as track outcomes.

Our review has several limitations. First, a number of studies may have been excluded from the final analysis due to our interpretation of the published research methods. As a result, some mobile outcomes related to specific therapeutic or disease conditions were not summarized in our review. For example, in our original search we retrieved over 96 references that were related to Parkinson's disease. The vast majority of these studies were excluded from our final review because the mobile outcomes (e.g., freezing of gait, bradykinesia, postural sway, tremor, etc.) were not used in the context of a clinical research study (one of our inclusion criteria). In all, over 70\% of the 96 Parkinson's disease-related references retrieved in our initial literature search focused on the development of mobile devices and pertinent algorithms to collect clinical outcomes related to Parkinson's disease, and all but $2[13,46]$ of the remaining references described studies conducted solely in controlled clinic-based environments (one of our exclusion criteria). This demonstrates the vast amount of effort that has gone into the development and refinement of mobile outcome assessments for this disease condition and the wealth of scientific evidence that supports the use and application of mobile technologies in future Parkinson's disease clinical research studies. There are a number of recommended literature reviews that focus on identifying and consolidating the evidence supporting these Parkinson's disease-related outcomes [47-50], including the specific technologies used in these trials $[47,49,51]$, and the validation processes used to ensure accurate and reliable measurements [52].

Second, during the screening process we identified numerous studies that did not meet our inclusion criteria, but these studies suggest that the use of mobile devices in clinical research is rich with early-stage studies (e.g., validation and feasibility studies) to develop new mobile outcomes, validate the analytical operability of technologies, and determine the feasibility of applying these new outcomes and technologies in clinical trials. Validations within these studies include comparisons of healthy subjects and patients with target conditions to assess predictive capabilities of mobile outcomes, comparisons of mobile outcomes with conventionally measured outcomes, studies refining algorithms to interpret mobile outcomes, and studies clarifying the link between mobile outcomes and clinically meaningful endpoints. These developments suggest that the use of mobile devices in clinical trials is likely to see significant growth in the near future.

Finally, this review is limited to studies indexed in PubMed. Anecdotally, we are aware of dozens of studies using mobile devices to measure clinical outcomes and biomarkers 
Perry et al.: Use of Mobile Devices to Measure Outcomes in Clinical Research, 2010-2016: A Systematic Literature Review

conducted by industry sponsors and device manufacturers that have not been published in the peer-reviewed literature. Therefore, this review likely underreports the use of mobile outcomes in clinical research.

\section{Conclusion}

Mobile devices are being widely used in clinical research, although their use in interventional research to assess therapeutic effectiveness is limited. For mobile devices to be used more frequently in regulatory interventional research, it is important to emphasize validating, or consolidating, evidence on the clinical meaningfulness of the mobile outcome assessments identified in this review. The wealth of peer-reviewed publications reporting observational research using mobile outcome assessments indicates that such efforts are already underway. To further support that aim, CTTI has developed recommendations and tools that may be helpful for selecting appropriate mobile outcomes as future clinical trial endpoints. We refer readers to CTTI's full set of recommendations and tools for additional information (https://www.ctti-clinicaltrials.org/projects/novel-endpoints) [4].

\section{Acknowledgements}

The authors would like to thank everyone who has participated in the CTTI Mobile Clinical Trials: Novel Endpoints project. Editing assistance was provided by Stephen Carlson, $\mathrm{PhD}$, in affiliation with Whitsell Innovations, Inc.

\section{Statement of Ethics}

The authors have no ethical conflicts to disclose.

\section{Disclosure Statement}

The authors declare no conflicts of interest.

\section{Funding Sources}

Funding for this article was made possible, in part, by the US Food and Drug Administration through grant R18FD005292 and cooperative agreement U19FD003800. Views expressed in publications do not necessarily reflect the official policies of the US Department of Health and Human Services, nor does any mention of trade names, commercial practices, or organization imply endorsement by the US Government. Partial funding was also provided by pooled membership fees and in-kind contributions from CTTI's member organizations. 


\section{Appendix 1}

\begin{tabular}{|c|c|c|}
\hline Layer & Search terms & Results, $n$ \\
\hline$\# 1$ & 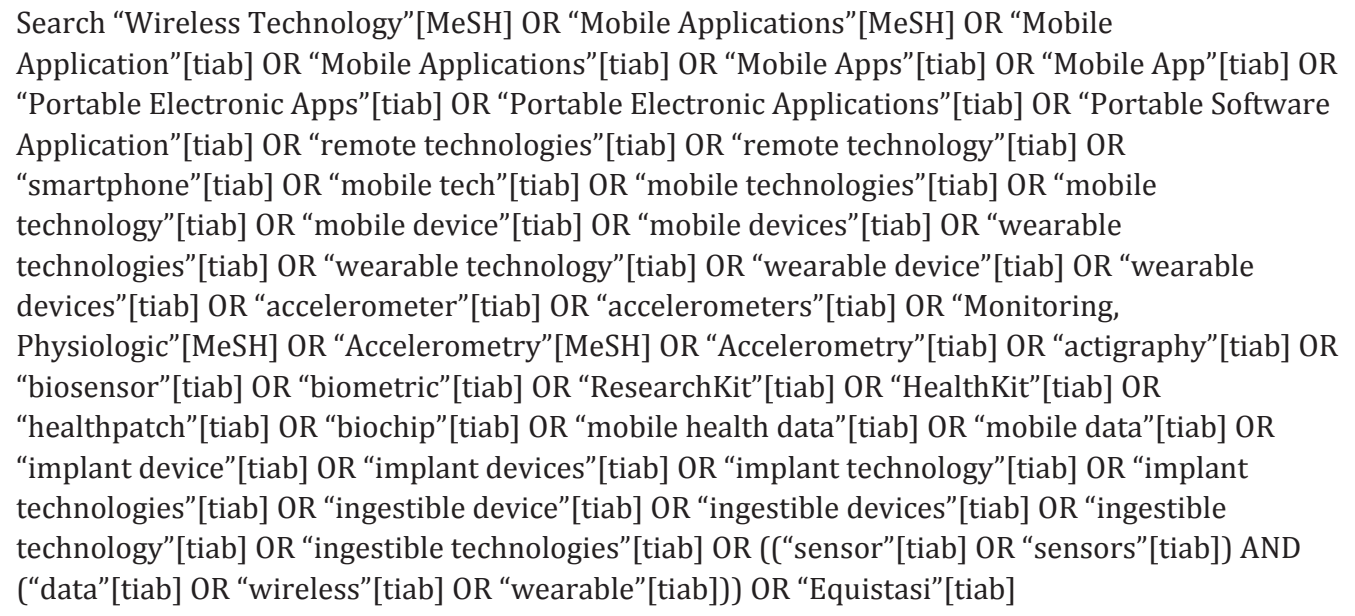 & 190,845 \\
\hline$\# 2$ & $\begin{array}{l}\text { Search wear[tiab] OR worn[tiab] OR wearable[tiab] OR wearing[tiab] OR “Signal Processing, } \\
\text { Computer-Assisted”[MeSH] OR ((Wireless[tiab] OR remote[tiab]) AND (monitor[tiab] OR } \\
\text { monitors[tiab] OR monitoring[tiab] OR diagnosis[tiab] OR diagnose[tiab])) }\end{array}$ & 108,556 \\
\hline$\# 3$ & \#1 AND \#2 & 13,234 \\
\hline$\# 4$ & 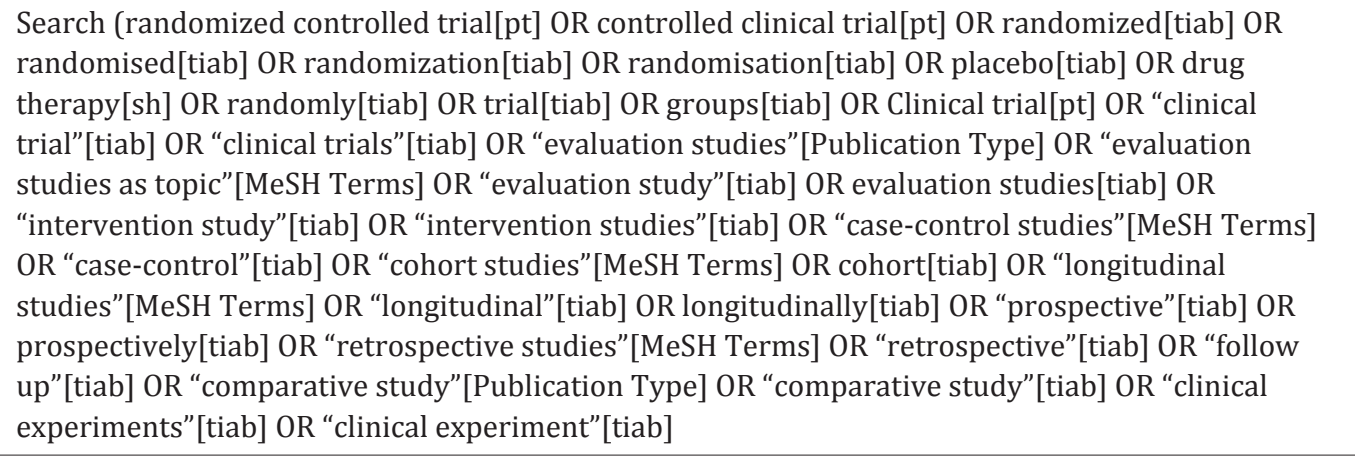 & $7,195,858$ \\
\hline$\# 5$ & \#3 AND \#4 & 5,534 \\
\hline \#6 & $\begin{array}{l}\text { \#5 NOT (Editorial[ptyp] OR Letter[ptyp] OR Case Reports[ptyp] OR “a case study”[ti] OR } \\
\text { “: case study”[ti] OR "case study: ” OR Comment[ptyp]) NOT (animals[mh] NOT humans[mh]) } \\
\text { AND (“2010/01/01"[PDat] : “3000/12/31"[PDat]) AND English[lang] }\end{array}$ & 2,530 \\
\hline
\end{tabular}

\section{References}

1 Dorsey ER, Venuto C, Venkataraman V, Harris DA, Kieburtz K: Novel methods and technologies for 21st-century clinical trials: a review. JAMA Neurol 2015;72:582-588.

2 Walton MK, Powers JH 3rd, Hobart J, Patrick D, Marquis P, Vamvakas S, et al; International Society for Pharmacoeconomics and Outcomes Research Task Force for Clinical Outcomes Assessment: Clinical outcome assessments: conceptual foundation - report of the ISPOR Clinical Outcomes Assessment - Emerging Good Practices for Outcomes Research Task Force. Value Health 2015;18:741-752.

3 FDA: BEST (Biomarkers, EndpointS, and other Tools) Resource. Silver Spring, Food and Drug Administration, co-published by National Institutes of Health (US), Bethesda, 2016. https://www.ncbi.nlm.nih.gov/books/ NBK338448/.

4 Clinical Trials Transformation Initiative: Mobile Clinical Trials (MCT): Novel Endpoints. https://www.ctticlinicaltrials.org/projects/novel-endpoints (cited July 17, 2017). 


\begin{tabular}{|c|c|}
\hline Digit Biomark 2018;2:11-30 & \\
\hline DOI: $10.1159 / 000486347$ & $\begin{array}{l}\text { (c) } 2018 \text { The Author(s). Published by S. Karger AG, Basel } \\
\text { www.karger.com/dib }\end{array}$ \\
\hline
\end{tabular}

Perry et al.: Use of Mobile Devices to Measure Outcomes in Clinical Research 2010-2016: A Systematic Literature Review

5 QSR International Pyt Ltd. NVivo 11 for Windows. 11.1.0.411 (32-bit) ed2015.

6 NLM/NIH: Learn about clinical studies. 2017. https://clinicaltrials.gov/ct2/about-studies/learn.

7 US Food and Drug Administration: What Are the Different Types of Clinical Research? 2016. https://www.fda. gov/forpatients/clinicaltrials/types/default.htm (November 12, 2016).

8 Albright CL, Steffen AD, Wilkens LR, White KK, Novotny R, Nigg CR, et al: Effectiveness of a 12-month randomized clinical trial to increase physical activity in multiethnic postpartum women: results from Hawaii's Nā Mikimiki Project. Prev Med 2014;69:214-223.

-9 Biltoft-Jensen A, Hjorth MF, Trolle E, Christensen T, Brockhoff PB, Andersen LF, et al: Comparison of estimated energy intake using Web-based Dietary Assessment Software with accelerometer-determined energy expenditure in children. Food Nutr Res 2013;57:21434.

10 Hou MY, Hurwitz S, Kavanagh E, Fortin J, Goldberg AB: Using daily text-message reminders to improve adherence with oral contraceptives: a randomized controlled trial. Obstet Gynecol 2010;116:633-640.

11 Kovatchev BP, Renard E, Cobelli C, Zisser HC, Keith-Hynes P, Anderson SM, et al: Safety of outpatient closed-loop control: first randomized crossover trials of a wearable artificial pancreas. Diabetes Care 2014;37:1789-1796.

12 Turksoy K, Quinn LT, Littlejohn E, Cinar A: An integrated multivariable artificial pancreas control system. J Diabetes Sci Technol 2014;8:498-507.

13 Ginis P, Nieuwboer A, Dorfman M, Ferrari A, Gazit E, Canning CG, et al: Feasibility and effects of home-based smartphone-delivered automated feedback training for gait in people with Parkinson's disease: a pilot randomized controlled trial. Parkinsonism Relat Disord 2016;22:28-34.

14 Hartman SJ, Natarajan L, Palmer BW, Parker B, Patterson RE, Sears DD: Impact of increasing physical activity on cognitive functioning in breast cancer survivors: rationale and study design of Memory \& Motion. Contemp Clin Trials 2015;45:371-376.

15 Kay DB, Buysse DJ, Germain A, Hall M, Monk TH: Subjective-objective sleep discrepancy among older adults: associations with insomnia diagnosis and insomnia treatment. J Sleep Res 2015;24:32-39.

16 Murphy SL, Lyden AK, Clary M, Geisser ME, Yung RL, Clauw DJ, et al: Activity pacing for osteoarthritis symptom management: study design and methodology of a randomized trial testing a tailored clinical approach using accelerometers for veterans and non-veterans. BMC Musculoskelet Disord 2011;12:177.

17 Panza GA, Taylor BA, Thompson PD, Erhard L, Capizzi JA, Grimaldi AS, et al: The effect of atorvastatin on habitual physical activity among healthy adults. Med Sci Sports Exerc 2016;48:1-6.

18 Phillips SM, McAuley E: Physical activity and fatigue in breast cancer survivors: a panel model examining the role of self-efficacy and depression. Cancer Epidemiol Biomarkers Prev 2013;22:773-781.

19 Redfield MM, Anstrom KJ, Levine JA, Koepp GA, Borlaug BA, Chen HH, et al: Isosorbide mononitrate in heart failure with preserved ejection fraction. N Engl J Med 2015;373:2314-2324.

20 Rondanelli M, Opizzi A, Monteferrario F, Antoniello N, Manni R, Klersy C: The effect of melatonin, magnesium, and zinc on primary insomnia in long-term care facility residents in Italy: a double-blind, placebo-controlled clinical trial. J Am Geriatr Soc 2011;59:82-90.

21 Sasseville A, Hebert M: Using blue-green light at night and blue-blockers during the day to improves adaptation to night work: a pilot study. Prog Neuropsychopharmacol Biol Psychiatry 2010;34:1236-1242.

-22 Taraldsen K, Sletvold O, Thingstad P, Saltvedt I, Granat MH, Lydersen S, et al: Physical behavior and function early after hip fracture surgery in patients receiving comprehensive geriatric care or orthopedic care - a randomized controlled trial. J Gerontol A Biol Sci Med Sci 2014;69:338-345.

23 van der Meij BS, Langius JA, Spreeuwenberg MD, Slootmaker SM, Paul MA, Smit EF, et al: Oral nutritional supplements containing n-3 polyunsaturated fatty acids affect quality of life and functional status in lung cancer patients during multimodality treatment: an RCT. Eur J Clin Nutr 2012;66:399-404.

-24 Blauw H, van Bon AC, Koops R, DeVries JH; on behalf of the PCDIAB Consortium: Performance and safety of an integrated bihormonal artificial pancreas for fully automated glucose control at home. Diabetes Obes Metab 2016;18:671-677.

25 English C, Healy GN, Olds T, Parfitt G, Borkoles E, Coates A, et al: Reducing sitting time after stroke: a phase II safety and feasibility randomized controlled trial. Arch Phys Med Rehabil 2016;97:273-280.

26 Kropff J, Del Favero S, Place J, Toffanin C, Visentin R, Monaro M, et al: 2 month evening and night closed-loop glucose control in patients with type 1 diabetes under free-living conditions: a randomised crossover trial. Lancet Diabetes Endocrinol 2015;3:939-947.

27 Pulakka A, Ashorn U, Cheung YB, Dewey KG, Maleta K, Vosti SA, et al: Effect of 12-month intervention with lipid-based nutrient supplements on physical activity of 18-month-old Malawian children: a randomised, controlled trial. Eur J Clin Nutr 2015;69:173-178.

28 Russell SJ, El-Khatib FH, Sinha M, Magyar KL, McKeon K, Goergen LG, et al: Outpatient glycemic control with a bionic pancreas in type 1 diabetes. N Engl J Med 2014;371:313-325.

29 Vasiliadis KV, Viazis N, Vlachogiannakos J, Sgouros SN, Stefanidis G, Archimandritis A, et al: Efficacy of three different dosages of esomeprazole in the long-term management of reflux disease: a prospective, randomized study, using the wireless Bravo pH system. Am J Gastroenterol 2010;105:308-313.

-30 Jakicic JM, Gregg E, Knowler W, Kelley DE, Lang W, Miller GD, et al: Activity patterns of obese adults with type 2 diabetes in the Look AHEAD study. Med Sci Sports Exerc 2010;42:1995-2005.

-31 Miwa Y, Miyakoshi M, Hoshida K, Yanagisawa R, Abe A, Tsukada T, et al: Heart rate turbulence can predict cardiac mortality following myocardial infarction in patients with diabetes mellitus. J Cardiovasc Electrophysiol 2011;22:1135-1140. 


\begin{tabular}{|c|c|}
\hline Digit Biomark 2018;2:11-30 & \\
\hline DOI: 10.1159/000486347 & $\begin{array}{l}\text { (c) } 2018 \text { The Author(s). Published by S. Karger AG, Basel } \\
\text { www.karger.com/dib }\end{array}$ \\
\hline
\end{tabular}

Perry et al.: Use of Mobile Devices to Measure Outcomes in Clinical Research, 2010-2016: A Systematic Literature Review

32 Massa J, Stone KL, Wei EK, Harrison SL, Barrett-Connor E, Lane NE, et al: Vitamin D and actigraphic sleep outcomes in older community-dwelling men: the MrOS sleep study. Sleep 2015;38:251-257.

-33 Mosconi G, Colombo D, Graziani E, Franceschelli N, Roi GS, Totti V, et al: Physical performance in kidney transplanted patients: a study on desert trekking. J Biol Regul Homeost Agents 2011;25:417-425.

-34 Appleman K, Figueiro MG, Rea MS: Controlling light-dark exposure patterns rather than sleep schedules determines circadian phase. Sleep Med 2013;14:456-461.

-35 Hjorth MF, Chaput JP, Michaelsen K, Astrup A, Tetens I, Sjödin A: Seasonal variation in objectively measured physical activity, sedentary time, cardio-respiratory fitness and sleep duration among 8- to 11-year-old Danish children: a repeated-measures study. BMC Public Health 2013;13:808.

-36 Kushnir J, Cohen-Zrubavel V, Kushnir B: Night diapers use and sleep in children with enuresis. Sleep Med 2013;14:1013-1016.

-37 Lau CP, Gbadebo TD, Connolly SJ, Van Gelder IC, Capucci A, Gold MR, et al: Ethnic differences in atrial fibrillation identified using implanted cardiac devices. J Cardiovascular Electrophysiol 2013;24:381-387.

-38 Bennett MK, Shao M, Gorodeski EZ: Home monitoring of heart failure patients at risk for hospital readmission using a novel under-the-mattress piezoelectric sensor: a preliminary single centre experience. J Telemed Telecare 2017;23:60-67.

-39 Leu HB, Chung CM, Lin SJ, Lu TM, Yang HC, Ho HY, et al: A novel SNP associated with nighttime pulse pressure in young-onset hypertension patients could be a genetic prognostic factor for cardiovascular events in a general cohort in Taiwan. PLoS One 2014;9:e97919.

-40 Extramiana F, Dubois R, Vaglio M, Roussel P, Dreyfus G, Badilini F, et al: The time course of new T-wave ECG descriptors following single- and double-dose administration of sotalol in healthy subjects. Ann Noninvasive Electrocardiol 2010;15:26-35.

-41 Renard E, Farret A, Kropff J, Bruttomesso D, Messori M, Place J, et al; AP@home Consortium: Day and night closed-loop glucose control in patients with type 1 diabetes under free-living conditions: results of a singlearm 1-month experience compared with a previously reported feasibility study of evening and night at home. Diabetes Care 2016;39:1151-1160.

42 Johnson LF, DeMeester TR: Development of the 24-h intraesophageal pH monitoring composite scoring system. J Clin Gastroenterol 1986;8(suppl 1):52-58.

43 Kandulski A, Peitz U, Mönkemüller K, Neumann H, Weigt J, Malfertheiner P: GERD assessment including pH metry predicts a high response rate to PPI standard therapy. BMC Gastroenterol 2013;13:12.

44 King D, Hume PA, Brughelli M, Gissane C: Instrumented mouthguard acceleration analyses for head impacts in amateur rugby union players over a season of matches. Am J Sports Med 2015;43:614-624.

45 Strimbu K, Tavel JA: What are biomarkers? Curr Opin HIV AIDS 2010;5:463-466.

46 Weiss A, Herman T, Giladi N, Hausdorff JM: Objective assessment of fall risk in Parkinson's disease using a body-fixed sensor worn for 3 days. PLoS One 2014;9:e96675.

47 Maetzler W, Domingos J, Srulijes K, Ferreira JJ, Bloem BR: Quantitative wearable sensors for objective assessment of Parkinson's disease. Mov Disord 2013;28:1628-1637.

48 Horak FB, Mancini M: Objective biomarkers of balance and gait for Parkinson's disease using body-worn sensors. Mov Disord 2013;28:1544-1551.

49 Ossig C, Antonini A, Buhmann C, Classen J, Csoti I, Falkenburger B, et al: Wearable sensor-based objective assessment of motor symptoms in Parkinson's disease. J Neural Transm (Vienna) 2016;123:57-64.

50 Del Din S, Godfrey A, Galna B, Lord S, Rochester L: Free-living gait characteristics in ageing and Parkinson's disease: impact of environment and ambulatory bout length. J Neuroeng Rehabil 2016;13:46.

51 Godinho C, Domingos J, Cunha G, Santos AT, Fernandes RM, Abreu D, et al: A systematic review of the characteristics and validity of monitoring technologies to assess Parkinson's disease. J Neuroeng Rehabil 2016; $13: 24$.

-52 Del Din S, Godfrey A, Mazza C, Lord S, Rochester L: Free-living monitoring of Parkinson's disease: lessons from the field. Mov Disord 2016;31:1293-1313.

53 Alosco ML, Spitznagel MB, Cohen R, Raz N, Sweet LH, Josephson R, et al: Decreased physical activity predicts cognitive dysfunction and reduced cerebral blood flow in heart failure. J Neurol Sci 2014;339:169-175.

54 Buijs DM, Ramadi A, MacDonald K, Lightfoot R, Senaratne M, Haennel RG: Quantity and quality of daily physical activity in older cardiac patients. Can J Cardiovasc Nurs 2015;25:10-16.

55 English C, Healy GN, Coates A, Lewis L, Olds T, Bernhardt J: Sitting and activity time in people with stroke. Phys Ther 2016;96:193-201.

56 English C, Healy GN, Coates A, Lewis LK, Olds T, Bernhardt J: Sitting time and physical activity after stroke: physical ability is only part of the story. Top Stroke Rehabil 2016;23:36-42.

57 Ewalt LA, Danduran MJ, Strath SJ, Moerchen V, Swartz AM: Objectively assessed physical activity and sedentary behaviour does not differ between children and adolescents with and without a congenital heart defect: a pilot examination. Cardiol Young 2012;22:34-41.

-58 Fokkenrood HJ, Lauret GJ, Verhofstad N, Bendermacher BL, Scheltinga MR, Teijink JA: The effect of supervised exercise therapy on physical activity and ambulatory activities in patients with intermittent claudication. Eur J Vasc Endovasc Surg 2015;49:184-191.

59 Hamer M, Venuraju SM, Lahiri A, Rossi A, Steptoe A: Objectively assessed physical activity, sedentary time, and coronary artery calcification in healthy older adults. Arterioscler Thromb Vasc Biol 2012;32:500-505. 


\begin{tabular}{|c|c|}
\hline Digit Biomark 2018;2:11-30 & \\
\hline DOI: $10.1159 / 000486347$ & $\begin{array}{l}\text { (c) } 2018 \text { The Author(s). Published by S. Karger AG, Basel } \\
\text { www.karger.com/dib }\end{array}$ \\
\hline
\end{tabular}

Perry et al.: Use of Mobile Devices to Measure Outcomes in Clinical Research 2010-2016: A Systematic Literature Review

-60 Klenk J, Denkinger M, Nikolaus T, Peter R, Rothenbacher D, Koenig W: Association of objectively measured physical activity with established and novel cardiovascular biomarkers in elderly subjects: every step counts. J Epidemiol Community Health 2013;67:194-197.

-61 Lauret GJ, Fokkenrood HJ, Bendermacher BL, Scheltinga MR, Teijink JA: Physical activity monitoring in patients with intermittent claudication. Eur J Vasc Endovasc Surg 2014;47:656-663.

62 Marschollek M: Physical activity event regularity and health outcome - "undiscovered country" in cohort accelerometer data. Stud Health Technol Inform 2015;210:657-659.

63 Prince SA, Blanchard CM, Grace SL, Reid RD: Objectively-measured sedentary time and its association with markers of cardiometabolic health and fitness among cardiac rehabilitation graduates. Eur J Prev Cardiol 2016;23:818-825.

64 Cichosz SL, Fleischer J, Høyem P, Laugesen E, Poulsen PL, Christiansen JS, et al: Objective measurements of activity patterns in people with newly diagnosed type 2 diabetes demonstrate a sedentary lifestyle. Diabet Med 2013;30:1063-1066.

65 Desveaux L, Goldstein RS, Mathur S, Hassan A, Devlin M, Pauley T, et al: Physical activity in adults with diabetes following prosthetic rehabilitation. Can J Diabetes 2016;40:336-341.

66 Funck KL, Laugesen E, Høyem P, Fleischer J, Cichosz SL, Christiansen JS, et al: Low physical activity is associated with increased arterial stiffness in patients recently diagnosed with type 2 diabetes. Am J Hypertens 2016;29:882-888.

67 Barone Gibbs B, Pettee Gabriel K, Reis JP, Jakicic JM, Carnethon MR, Sternfeld B: Cross-sectional and longitudinal associations between objectively measured sedentary time and metabolic disease: the Coronary Artery Risk Development in Young Adults (CARDIA) study. Diabetes Care 2015;38:1835-1843.

-68 Gingras V, Vigneault J, Weisnagel SJ, Tchernof A, Robitaille J: Accelerometry-measured physical activity and inflammation after gestational diabetes. Med Sci Sports Exerc 2013;45:1307-1312.

69 Borich MR, Kimberley TJ: Using actigraphy and transcranial magnetic stimulation to assess the relationship between sleep and visuomotor skill learning. Restor Neurol Neurosci 2012;30:81-90.

-70 Chen WT, Lee SY, Shiu CS, Simoni JM, Pan C, Bao M, et al: Fatigue and sleep disturbance in HIV-positive women: a qualitative and biomedical approach. J Clin Nurs 2013;22:1262-1269.

-71 Meeus M, van Eupen I, van Baarle E, De Boeck V, Luyckx A, Kos D, et al: Symptom fluctuations and daily physical activity in patients with chronic fatigue syndrome: a case-control study. Arch Phys Med Rehabil 2011;92: 1820-1826.

-72 Bell JA, Hamer M, van Hees VT, Singh-Manoux A, Kivimaki M, Sabia S: Healthy obesity and objective physical activity. Am J Clin Nutr 2015;102:268-275.

-73 Cadmus-Bertram L, Marcus BH, Patterson RE, Parker BA, Morey BL: Use of the Fitbit to measure adherence to a physical activity intervention among overweight or obese, postmenopausal women: self-monitoring trajectory during 16 weeks. JMIR Mhealth and Uhealth 2015;3:e96.

74 Camhi SM, Crouter SE, Hayman LL, Must A, Lichtenstein AH: Lifestyle behaviors in metabolically healthy and unhealthy overweight and obese women: a preliminary study. PLoS One 2015;10:e0138548.

75 Golubic R, Wijndaele K, Sharp SJ, Simmons RK, Griffin SJ, Wareham NJ, et al: Physical activity, sedentary time and gain in overall and central body fat: 7-year follow-up of the ProActive trial cohort. Int J Obes (Lond) 2015; 39:142-148.

-76 Hayes L, McParlin C, Kinnunen TI, Poston L, Robson SC, Bell R; UPBEAT Consortium: Change in level of physical activity during pregnancy in obese women: findings from the UPBEAT pilot trial. BMC Pregnancy Childbirth 2015; $15: 52$.

77 Itoi A, Yamada Y, Watanabe Y, Kimura M: Physical activity, energy intake, and obesity prevalence among urban and rural schoolchildren aged 11-12 years in Japan. Appl Physiol Nutr Metab 2012;37:1189-1199.

-78 Janney CA, Ganguli R, Richardson CR, Holleman RG, Tang G, Cauley JA, et al: Sedentary behavior and psychiatric symptoms in overweight and obese adults with schizophrenia and schizoaffective disorders (WAIST Study). Schizophr Res 2013;145:63-68.

79 Kroemeke A, Zając-Gawlak I, Pośpiech D, Gába A, Přidalová M, Pelclová J: Postmenopausal obesity: 12,500 steps per day as a remedy? Relationships between body composition and daily steps in postmenopausal women. Prz Menopauzalny 2014;13:227-232.

80 Fisher SR, Goodwin JS, Protas EJ, Kuo YF, Graham JE, Ottenbacher KJ, et al: Ambulatory activity of older adults hospitalized with acute medical illness. J Am Geriatr Soc 2011;59:91-95.

-81 Jefferis BJ, Sartini C, Lee IM, Choi M, Amuzu A, Gutierrez C, et al: Adherence to physical activity guidelines in older adults, using objectively measured physical activity in a population-based study. BMC Public Health 2014; $14: 382$.

-82 Jefferis BJ, Merom D, Sartini C, Wannamethee SG, Ash S, Lennon LT, et al: Physical activity and falls in older men: the critical role of mobility limitations. Med Sci Sports Exerc 2015;47:2119-2128.

-83 Jefferis BJ, Sartini C, Ash S, Lennon LT, Wannamethee SG, Lee IM, et al: Trajectories of objectively measured physical activity in free-living older men. Med Sci Sports Exerc 2015;47:343-349.

84 Jefferis BJ, Sartini C, Shiroma E, Whincup PH, Wannamethee SG, Lee IM: Duration and breaks in sedentary behaviour: accelerometer data from 1,566 community-dwelling older men (British Regional Heart Study). Br J Sports Med 2015;49:1591-1594. 
Perry et al.: Use of Mobile Devices to Measure Outcomes in Clinical Research,

2010-2016: A Systematic Literature Review

-85 Klenk J, Kerse N, Rapp K, Nikolaus T, Becker C, Rothenbacher D, et al; ActiFE Study Group: Physical activity and different concepts of fall risk estimation in older people - results of the ActiFE-Ulm Study. PLoS One 2015; 10:e0129098.

-86 Klenk J, Dallmeier D, Denkinger MD, Rapp K, Koenig W, Rothenbacher D: Objectively measured walking duration and sedentary behaviour and four-year mortality in older people. PLoS One 2016;11:e0153779.

-87 Ku PW, Fox KR, Liao Y, Sun WJ, Chen LJ: Prospective associations of objectively assessed physical activity at different intensities with subjective well-being in older adults. Qual Life Res 2016;25:2909-2919.

88 Mai A, Bloch A, Klaassen-Mielke R, Platen P, Hinrichs T: Diurnal profiles of pedometer-determined physical activity in chronically ill and mobility-limited older adults: a cross-sectional study. BMC Public Health 2014; 14:1268.

89 Filipović Grčić P, Matijaca M, Lušić I, Čapkun V: Responsiveness of walking-based outcome measures after multiple sclerosis relapses following steroid pulses. Med Sci Monit 2011;17:CR704-CR710.

-90 Dallal CM, Brinton LA, Matthews CE, Pfeiffer RM, Hartman TJ, Lissowska J, et al: Association of active and sedentary behaviors with postmenopausal estrogen metabolism. Med Sci Sports Exerc 2016;48:439-448.

-91 Hawkins M, Pekow P, Chasan-Taber L: Physical activity, sedentary behavior, and C-reactive protein in pregnancy. Med Sci Sports Exerc 2014;46:284-292.

$\$ 92$ Ceroni D, Martin X, Lamah L, Delhumeau C, Farpour-Lambert N, De Coulon G, et al: Recovery of physical activity levels in adolescents after lower limb fractures: a longitudinal, accelerometry-based activity monitor study. BMC Musculoskelet Disord 2012;13:131.

-93 Ilich SS, Dempsey AR, Mills PM, Sturnieks DL, Stachowiak GW, Maguire KF, et al: Physical activity patterns and function 3 months after arthroscopic partial meniscectomy. J Sci Med Sport 2013;16:195-199.

$\$ 94$ Tully MA, Bleakley CM, O’Connor SR, McDonough SM: Functional management of ankle sprains: what volume and intensity of walking is undertaken in the first week postinjury. Br J Sports Med 2012;46:877-882.

95 Ehsan M, Khan R, Wakefield D, Qureshi A, Murray L, Zuwallack R, et al: A longitudinal study evaluating the effect of exacerbations on physical activity in patients with chronic obstructive pulmonary disease. Ann Am Thorac Soc 2013;10:559-564.

-96 Eliason G, Zakrisson AB, Piehl-Aulin K, Hurtig-Wennlöf A: Physical activity patterns in patients in different stages of chronic obstructive pulmonary disease. COPD 2011;8:369-374.

$\$ 97$ Janaudis-Ferreira T, Mathur S, Romano JM, Goldstein RS, Brooks D: Arm activity during daily life in individuals with chronic obstructive pulmonary disease. J Cardiopulm Rehabil Prev 2016;36:125-131.

98 Hashimoto T, Yoshiuchi K, Inada S, Shirakura K, Wada N, Takeuchi K, et al: Physical activity of elderly patients with rheumatoid arthritis and healthy individuals: an actigraphy study. Biopsychosoc Med 2015;9:19.

-99 Hatzinger M, Brand S, Perren S, Stadelmann S, von Wyl A, von Klitzing K, et al: Sleep actigraphy pattern and behavioral/emotional difficulties in kindergarten children: association with hypothalamic-pituitary-adrenocortical (HPA) activity. J Psychiatr Res 2010;44:253-261.

100 Kim J, Nakamura T, Kikuchi H, Yoshiuchi K, Sasaki T, Yamamoto Y: Covariation of depressive mood and spontaneous physical activity in major depressive disorder: toward continuous monitoring of depressive mood. IEEE J Biomed Health Inform 2015;19:1347-1355.

101 Cupisti A, Capitanini A, Betti G, D’Alessandro C, Barsotti G: Assessment of habitual physical activity and energy expenditure in dialysis patients and relationships to nutritional parameters. Clin Nephrol 2011;75:218-225.

102 Carson V, Salmon J, Crawford D, Hinkley T, Hesketh KD: Longitudinal levels and bouts of objectively measured sedentary time among young Australian children in the HAPPY study. J Sci Med Sport 2016;19:232-236.

103 Ridgers ND, Salmon J, Timperio A: Too hot to move? Objectively assessed seasonal changes in Australian children's physical activity. Int J Behav Nutr Phys Act 2015;12:77. 